\title{
Frames COVID-19 no Estado de Emergência: análise dos editoriais de très jornais portugueses
}

Francisco Fontes

\author{
Ceis20 - Universidade de Coimbra - cardosofontes@gmail.com
}

\begin{abstract}
Resumo
Este artigo analisa os editoriais que três media portugueses publicaram sobre a COVID-19, procurando perceber os modos como o tema é enquadrado e percecionado no discurso público.

Se o editorial é o género jornalístico que expressa a ideologia do jornal, através dele pode vislumbrar-se que mensagens, interpretações e posicionamentos são assumidos e colocados à discussão no espaço público.

Os três media escolhidos foram o jornal diário Público, a revista semanal Visão e o semanário regional da Beira Baixa Reconquista, todos eles de informação generalista. Dos dois de difusão nacional foram selecionados os editoriais das edições impressa e digital, e do regional,

de inspiração cristã, apenas os da edição em papel. Definiram-se dois períodos de análise durante o Estado de Emergência, março de 2020 e janeiro de 2021, meses do primeiro e do segundo confinamento geral da população. O corpus é constituído por 48 editoriais, 30 do primeiro confinamento e 18 do segundo, sendo 41 do Público, cinco da Visão e dois do Reconquista.

Da análise realizada conclui-se que do primeiro para o segundo período se alteram os temas e enquadramentos (frames), e que o posicionamento maioritariamente positivo, em março de 2020, muda para negativo em janeiro de 2021, a penalizar as falhas na gestão política e sanitária da pandemia.
\end{abstract}

Palavras-chave: COVID-19, estado de emergência, enquadramento, editorial, Público, Visão, Reconquista.

\section{COVID-19 frames in the State of Emergency: analysis of the editorials of three Portuguese newspapers}

\begin{abstract}
This article analyses the editorials on COVID19 published by three Portuguese media in order to understand how the topic is framed and perceived in public discourse. Being the editorial the journalistic genre that expresses the ideology of the newspaper, it can be shown that messages, interpretations and positions are assumed and put up for discussion in the public space.
\end{abstract}

Abstract
The three media chosen were the national daily newspaper Público, the national weekly magazine Visão and a regional weekly magazine of Beira Baixa, Reconquista, all of which present generalist information. From Público and Visão, the printed and the online version were selected, and the print version from the regional, Christian inspired magazine Reconquista. Two review periods during the state

(C) do(s) Autor(s) 2021. Artigo publicado online, em acesso aberto, por Interações: Sociedade e as Novas Modernidades, ISSN: 2184-3929, em https://interacoes-ismt.com, nos termos da Licença Internacional Creative Commons Attribuiçao-NãoCommercial 4.0 (https://creativecommons.org/ 
Frames COVID-I9 no Estado de Emergència:

análise dos editoriais de três jornais portugueses

of emergency were defined: March 2020 and January 2021, dates which correspond to the first and the second general lockdown. The corpus consists of 48 editorials, 30 from the first lockdown and 18 from the second, with 41 from Público, five from Visão and two from Reconquista.
The analysis shows that themes and frames change from the first to the second period, and that the mostly positive positions in March 2020 shifted to negative in January 2021, penalising failures in the political and health management of the pandemic.

Keywords: COVID-19, State of Emergency, framing, editorial, Público, Visão, Reconquista

\section{INTRODUÇÃO}

A comunicação, nas mais diversas formas em que se apresenta, é um elemento central e estruturante da vida em sociedade. É reconhecido que os meios de comunicação social desempenham uma função decisiva na transmissão de informações, ideias e conhecimentos. Contribuem, também, desse modo, para que trocas interlocutivas se possam desenvolver no espaço público, concretizando um ideal de democracia deliberativa, se os cidadãos estiverem informados, se participarem de forma livre e racional, para debater pontos de vista e tomarem decisões sobre o que é justo, tal como idealizou Jürgen Habermas (1997, p. 323).

O presente estudo centra-se na análise do enquadramento de editoriais sobre a pandemia COVID-19 produzidos por três órgãos de comunicação social portugueses de informação generalista: o diário Público e a revista semanal Visão, ambos de carácter nacional, nas suas plataformas impressa e digital, e o semanário regional da Beira Baixa Reconquista, de inspiração cristã e com sede em Castelo Branco, apenas na edição impressa.

Definiram-se dois períodos de análise no Estado de Emergência que vigorou em Portugal: o primeiro mês do primeiro confinamento obrigatório geral da população, março de 2020, e o primeiro mês do segundo confinamento obrigatório geral, janeiro de 2021. Foram recolhidos e analisados 48 editoriais, 30 no primeiro confinamento e 18 no segundo. Selecionaram-se os editoriais que tiveram como tema central a pandemia da COVID-19. No total dos dois períodos foram identificadas 41 publicações no Público, cinco na Visão e duas no Reconquista. 
Durante os períodos abrangidos no estudo, o tema COVID-19 dominou de forma esmagadora a produção jornalística, como atesta um relatório sobre os efeitos do Estado de Emergência no jornalismo em Portugal. Nele se refere que "ocupou 68\% dos profissionais que desenvolviam a atividade. Destes jornalistas, 39,3\% disseram que o tema da COVID-19 representou três quartos do seu trabalho e $29 \%$ afirmaram que só trataram questões relacionadas com este assunto. Apenas 4,4\% dos jornalistas inquiridos afirmaram não se ter dedicado a tratar temas da COVID-19 (Camponez, et al., 2020).

A história da humanidade regista graves crises epidémicas, umas mais circunscritas e outras mais gerais, mas nenhuma delas atingiu uma dimensão globalizada como a do coronavírus, que recebeu a designação comum de COVID-19.

Os primeiros casos foram identificados em 2019 na região de Wuhan, na China, como uma pneumonia de causas desconhecidas. Rapidamente desencadearam um surto epidémico de escala mundial, impossível de conter, pela incapacidade em identificar cadeias de contágio através dos contactos sociais. Perante a calamidade pública, uns atrás dos outros, os países interrompem a circulação internacional de pessoas, encerram atividades comerciais, instituições públicas, suspendem cultos religiosos, espetáculos desportivos e culturais, impõem o teletrabalho e declaram o Estado de Emergência, remetendo as pessoas para confinamento obrigatório nas suas residências, como medida de salvaguarda da saúde.

Em Portugal, o primeiro caso de infeção foi anunciado pela Direção-Geral da Saúde (DGS) a 2 de março de 2020, correspondendo a um cidadão que regressara de uma estadia em Espanha. No entanto, no dia anterior, a DGS alertava que o escritor chileno Luís Sepúlveda, que dias antes participara na Póvoa de Varzim no evento literário Correntes d'Escritas, se encontrava internado com COVID-19 em Espanha. O escritor acabou por falecer pouco tempo depois.

O primeiro óbito pela doença em Portugal aconteceu a 16 de março, dois dias antes de se iniciar o confinamento geral da população na sequência da declaração do Estado de Emergência pelo Presidente da República.

O relatório da situação epidemiológica em Portugal revelava que até 31de março de 2020 tinham ocorrido 187 óbitos e havia 46.248 casos de infeção confirmados.

O plano de vacinação COVID-19 é apresentado oficialmente a 3 de dezembro de 2020 para se iniciar em janeiro de 2121.

Em janeiro de 2021, em Portugal a doença começa a bater os recordes, dia após dia, em número de novos casos de infeção e de mortes. A gravidade da situação força, 
Frames COVID-I9 no Estado de Emergència:

análise dos editoriais de très jornais portugueses

a 15 de janeiro, a novo confinamento geral da população. Só neste mês de janeiro de 2021 foram registados 44\% (5.576) dos totais de óbitos contabilizados desde março do ano anterior.

A 31 de janeiro de 2021, o total de mortes por COVID-19 era de 12.757 e os casos de infeção totalizavam 726.321 .

A restrição de direitos fundamentais em sociedades democráticas como a portuguesa, pela dimensão do confinamento, do isolamento e da obrigação de uso de proteção individual suscitou reflexões críticas no espaço público, que se tornaram acaloradas quando associadas a práticas de desinformação.

Todas as epidemias registadas ao longo da história da Humanidade provocaram idêntica reação, com os negacionistas a alegarem que as guerras e outras doenças provocam mais mortes, os alarmistas "anunciando mais um fim do mundo", a comunidade científica dividida quanto ao mal, diagnóstico e cura, os políticos, para se resguardarem, a rodearem-se de "sábios e peritos e que acabam por ficar com a decisão (ou a indecisão nas mãos", e os “"activistas», que vão escolhendo vítimas e culpados para fins de manipulação política ou ideológica” (Pinto, 2020, p. 295).

Nestes tempos de pandemia da COVID-19, para o sociólogo José Luís Garcia, o jornalismo foi "um intermediário insubstituível para desmontar o caudal de mentira organizada" difundida pelos media sociais, em conteúdos de desinformação disseminados pela Internet, sobre a origem do coronavírus como arma biológica, sobre as formas de contágio, ou sobre tratamentos naturais (2020, p. 11).

Num estudo realizado em Portugal através de questionário a leitores, conclui-se que as empresas jornalísticas são mais confiáveis para obter informações sobre o coronavírus, ao invés das plataformas de redes sociais, "referidas como menos confiáveis, ao serem assinaladas como merecendo maior confiança por apenas $4 \%$ dos indivíduos inquiridos" (Ferreira, 2020, p. 43).

[N]um ecossistema mediático que ao longo dos últimos anos vinha a ser atormentado por crises progressivas de credibilidade, a presente pandemia recentrou o jornalismo naquele que era o seu lugar natural - ao ponto de ser apontado como antídoto para a presente infodemia. Cabe-lhe responder de forma adequada ao "voto de confiança" que a sociedade lhe concedeu (Ferreira, 2020, p. 47). 


\section{A AGENDA MEDIÁTICA E O ESPAÇO PÚBLICO}

Uma das funções do jornalismo é a de "servir de fórum para a crítica e o comentário públicos", assumindo-se como "árbitro e intermediário honesto" no debate público (Kovach \& Rosenstiel, 2004, pp. 138-139).

Na vida quotidiana, conhecer para além daquilo que cada cidadão apreende pela observação direta é decisivo para se poder orientar e tomar as melhores decisões. $\mathrm{O}$ jornalismo apresenta-se como o meio de narrar de modo factual acontecimentos do mundo que importa conhecer, socorrendo-se de um saber próprio e de um conjunto de valores e normas profissionais. O seu compromisso é com a verdade, numa "relação simbiótica" com a democracia, "residindo no núcleo dessa relação o conceito de liberdade" (Traquina, 2007, p. 135).

A função do jornalista, ou o poder do jornalismo, como alguns sociólogos dos media preferem designar, consiste na aplicação de um filtro, uma maneira de ver, que lhe permite identificar e extrair da realidade os acontecimentos que se devem tornar notícia, ou seja, aquilo que os cidadãos precisam de conhecer.

Os jornalistas - nas palavras do sociólogo francês Pierre Bourdieu - "têm 'óculos' especiais a partir dos quais veem certas coisas e não outras; e veem de certa maneira as coisas que veem e não outras" e, ainda, "eles operam uma seleção e uma construção do que é selecionado" (1997, p. 25).

Essas maneiras próprias de ver, selecionar, tratar e narrar a realidade radicam num conjunto de valores comuns, que conferem uma identidade própria ao grupo profissional.

Nelson Traquina identifica um conjunto de valores-notícia consensuais entre os jornalistas - em referência àquilo que Bourdieu designa de óculos especiais - que estão presentes em todo o processo de produção jornalística, desde a seleção dos acontecimentos à produção da notícia (2007, p. 186).

O mesmo investigador de media enumera os valores-notícia de seleção (critérios utilizados na seleção dos acontecimentos), os valores-notícia de construção (critérios de seleção dos elementos do acontecimento a incluir na elaboração da notícia) e os valores notícia e a organização jornalística (resultantes da influência da política editorial da empresa jornalística no processo de seleção dos acontecimentos) (Traquina, 2007, pp. 186-202).

Segundo Cristina Ponte, a transformação de um acontecimento em notícia resultará de "uma ponderação entre avaliações relativas a elementos de diferente peso, relevo e rigidez quanto aos processos produtivos" (Ponte, 2004, p. 129) 
Frames COVID-I9 no Estado de Emergència:

análise dos editoriais de três jornais portugueses

Na conceção de Gaye Tuchaman, socióloga norte-americana, os relatos dos acontecimentos, feitos pelos jornalistas, são estórias, e as estórias são frames da realidade (1999, pp. 258-261). De acordo com a mesma autora, o "trabalho jornalístico transforma as ocorrências quotidianas em acontecimentos informativos" (Tuchman, 2002, p. 93).

As tendências sociológicas modernas concebem as notícias como uma realidade construída, "como um fenómeno social partilhado, dado que no processo de descrição de um acontecimento, as notícias definem e moldam esse acontecimento" (Tuchman, 2002, p. 92).

Foi em 1972 que os sociólogos Maxwell McCombs e Donald L Shaw lançaram o conceito de agendamento mediático, e concluíam que aquilo que os media noticiavam influenciava o modo de pensar dos cidadãos.

[A]s consequências da marcação da agenda e do enquadramento dos media sugerem que os media não só nos dizem no que pensar, mas também como pensar nisso e, consequentemente, o que pensar.

A vasta literatura sobre o jornalismo reconhece o poder do jornalismo não apenas na projeção social dos tópicos mas também no seu poder de enquadrar esses tópicos como um recurso de discussão pública (Traquina, 2004, p. 13).

Estas questões remetem para os efeitos da comunicação jornalística, com implicações na compreensão do Espaço Público e da Opinião Pública.

Se os órgãos de comunicação social contribuem para estruturar o espaço público em torno da discussão de temas relevantes de interesse público, veem também a agenda mediática ser influenciada pela interação discursiva dos cidadãos. O espaço público é o resultado da interpenetração de agendas, da agenda dos cidadãos, da agenda política e da agenda dos media.

Segundo a conceção habermasiana, as esferas públicas desenvolvem-se em torno de temas pertinentes e significativos e, ao interpenetrarem-se com outros espaços públicos de discussão livre e racional, geram esferas públicas globais, que aprofundam um conhecimento de si próprio e da sociedade.

Nas esferas públicas, os processos de formação da opinião e da vontade são institucionalizados e, por mais especializados que possam ser, estão orientados para a difusão e a interpenetração (...). Todas as esferas públicas parciais remetem a uma esfera pública abrangente em que a sociedade em seu todo desenvolve um saber de si mesma. (Habermas, 2000, p. 500). 
A emergência dos media digitais comporta um potencial democratizador no espaço público, pelas maiores possibilidades de participação dos cidadãos, embora se questione se isso não implica também uma diluição do papel dos órgãos de comunicação social na sua função de agendamento.

No século XXI, o debate sobre as possibilidades de alargamento do espaço público, visando uma maior inclusão de temas e de perspetivas que contribuam para formar uma opinião pública mais qualificada, quer na expressão da "vontade popular", quer no que respeita à sua capacidade de vincular o poder político, desloca-se dos media tradicionais para os digitais (Borges, 2021, p. 33).

\section{O ENQUADRAMENTO (FRAMING)}

O conceito de enquadramento, ou framing, há várias décadas é objeto de estudo e utilizado em pesquisas na área das ciências sociais e humanas, nas quais se inclui a disciplina das Ciências da Comunicação.

As mais antigas conceptualizações de framing são associadas a Piaget, na década de 20 do século XX, em estudos de Psicologia. Três décadas mais tarde, aparecem as primeiras utilizações do termo frame nas Ciências Sociais e Humanas através do antropólogo Gregory Bateson (Gonçalves, 2011, p. 158).

Na Sociologia sobressaem os trabalhos de Erving Goffman, nos anos 1970 (Qin, 2015, p. 167), que faz do conceito título de uma das suas obras mais importantes, Frame Analysis (1974), na qual explica que aplica o termo 'quadro' (frame) "num sentido aproximado" ao de Bateson (Goffman, 2006, p. 7), em estudos de sociologia do quotidiano.

Goffman esclarece que quando utiliza a expressão 'quadro' quer mencionar os elementos básicos que consegue identificar, e que 'análise do quadro' [frame analysis] se reporta ao "exame da organização da experiência" (2006, p. 11). Afirma que com esse estudo não visava analisar a estrutura da vida social, apenas a "estrutura da experiência que os indivíduos têm em qualquer momento das suas vidas sociais" (Goffman, 2006, p. 14).

Desse modo, ao enquadrar põe-se em prática uma estratégia cognitiva para interpretar e organizar a perceção da realidade social, e para lhe atribuir significados, segundo a experiência de cada um, como indivíduo e como membro da sociedade. 
Frames COVID-I9 no Estado de Emergència:

análise dos editoriais de très jornais portugueses

Os enquadramentos, ou frames, assumem-se como princípios orientadores das experiências humanas. Articulam a interação, a experiência dos interlocutores e definem a dimensão cognitiva da participação em situações sociais.

$\mathrm{O}$ recorte da realidade que os media fazem, recorrendo a quadros interpretativos e explicativos, para que determinado tema possa ser apreendido, é suscetível de provocar determinados efeitos nas audiências.

Para João Pissarra Esteves, "toda a prática de comunicação se desenvolve a partir (no interior) de um dado quadro simbólico (frame), sendo este definido precisamente pela (e na) interação" (2011, p. 85).

$\mathrm{Na}$ interação podemos distinguir uma dimensão física/material, constituída pelos indivíduos propriamente ditos e pelos espaços físicos concretos da sua existência, e uma dimensão simbólica, que é constituída, esta, pelos chamados frames: os quadros simbólicos que ordenam a interação, a partir dos quais e em função dos quais os participantes se assumem como sujeitos da comunicação (Esteves, 2011, p. 83).

Cada ator social organiza o quadro de acordo com as suas experiências e perceções, daí resultando que as possibilidades de enquadramento sejam múltiplas. É a partir delas que se orientam as ações dos indivíduos, de grupos sociais, e das próprias sociedades.

Robert M. Entman (1993, p. 54) afirma que a noção de enquadramento nos indica que o quadro tem um efeito geral em grandes setores de público, embora possa não produzir um efeito universal em todos.

Enquadramento envolve essencialmente seleção e saliência. Enquadrar é selecionar alguns aspetos da realidade apercebida e torná-los mais salientes num texto de comunicação, de modo a promover uma definição de problemas particulares, interpretação causal, avaliação moral e/ou recomendação de tratamento para o item descrito (Entman, 1993, p. 52).

Para João Pissarra Esteves, a comunicação "significa partilha de significações, dentro de um dado quadro de sentido mais amplo", enquanto que a informação, "de modo diferente, é basicamente uma operação técnica e prossegue fins instrumentais: o seu valor é contingente, em função do maior ou menor sucesso que a própria infor- 
mação pode revestir para o fluxo muito complexo de movimentos que constituem as interacções" (2011, p. 86).

Os "enquadramentos" são um elemento fundamental na comunicação política, pelo que as elites competem entre si pelo estabelecimento de frames no espaço público. São um elemento fundamental, também, no exercício que o jornalista faz da sua profissão, no sentido de que lhe não compete repetir acriticamente $o$ que dizem as fontes, nem reproduzir os debates nos termos próprios destas, mas criar espaços plurais de diálogo e reflexão onde o máximo possível de perspetivas possa ser trazido ao espaço público e aí submetido a escrutínio (Gradim, 2016, p. 73).

A socióloga norte-americana Gaye Tuchman, nos anos 1970, transpôs para os estudos do jornalismo o conceito de enquadramento de Goffman, intercetando a sua aplicação com análises recolhidas do campo da sociologia das ocupações e das profissões.

Pretendeu mostrar que, para a definição dos enquadramentos, não podem ser negligenciadas influências estruturais do processo de seleção e produção das notícias, das organizações jornalísticas, das rotinas produtivas e da própria ideologia dos jornalistas (Tuchman, 1985, p. 230).

Tuchman entende que a abordagem noticiosa segundo a "metáfora da janela-enquadramento" põe em realce a atividade dos jornalistas e das suas empresas, "em vez de normas sociais, uma vez que não pressupõe que a estrutura social produz normas claramente definidas que determinam o que é digno de notícia” (2002, p. 92).

Apesar de alguma indeterminação conceptual, ao ponto de Robert Entman (1993, p. 51) o caracterizar como "paradigma fraturado", por agregar contributos de áreas tão distintas como a sociologia, retórica, semiótica, psicologia ou análise do discurso, o framing é de grande aplicação aos estudos dos media.

O editorial, que neste artigo é objeto de análise, é considerado o texto jornalístico de caráter opinativo que apresenta aos leitores a ideologia do jornal, a interpretação que faz e o posicionamento que assume sobre a atualidade noticiosa que narra nas suas páginas.

O jornal não serve só para relatar de forma isenta factos e acontecimentos, pode e deve pronunciar-se sobre esses factos, tentando extrair deles o seu real 
Frames COVID-I9 no Estado de Emergència:

análise dos editoriais de très jornais portugueses

significado, as relações que estabelecem com outros acontecimentos, e as consequências que poderão vir a ter na vida das pessoas - e isto é atribuir-lhes uma dimensão radicalmente nova em relação ao tratamento noticioso: a dimensão de profundidade (Gradim, 2000, p. 82).

Este artigo propõe-se analisar os editoriais relacionados com a COVID-19 que os media portugueses publicaram e os modos como o tema é enquadrado e percecionado no discurso público. Pese uma certa indefinição conceptual pela aplicação interdisciplinar do enquadramento, entendemos ser uma ferramenta capaz de viabilizar uma análise dos discursos dos diretores, bem como das construções simbólicas, crenças e valores que expressam como representantes da opinião dos seus órgãos de comunicação sociais.

\section{O EDITORIAL}

O editorial é o "porta-voz da linha ideológica da publicação" (Armañanzas \& Noci, 1996, p. 93). Aos editoriais são atribuídas diversas funções, e por se tratar de um género jornalístico, estabelece sempre relação com a atualidade.

"O editorial informa sempre sobre o acontecimento sobre o qual vai opinar" (Armañanzas \& Noci, 1996, p. 95), mas por não se tratar de um texto informativo não se detém na narração dos factos.

O editorial é a opinião do jornal acerca das notícias que publica. (...) A notícia dá parte do sucedido; o editorial interpreta o sentido do ocorrido e previne acerca do que é mais profundo, antecipando o que pode suceder dum momento para o outro. O jornalista ajuda os leitores a saber. O editorialista ajuda os leitores a compreender. $\mathrm{O}$ artigo explica, avalia e interpreta um facto noticioso de importância relevante segundo a convicção duma ordem superior representativa da postura ideológica do jornal (Letria, 1999, pp. 68-69).

Armañanzas \& Noci (1996, p. 94) apontam quatro funções do editorial: explicar os factos, fazer a contextualização histórica, prever o futuro e formular juízos.

Ao formularem juízos, os editorialistas assumem-se "guardiães não oficiais da consciência pública", com a tarefa de clarificar os factos, "analisar problemas comple- 
xos e fornecer esclarecimentos sobre situações complexas" (Armañanzas \& Noci, 1996, p. 94).

Face à natureza e ao alcance do editorial, a sua escrita é confiada a quem se identifica com "a linha política da direção ou dos proprietários da empresa", e em certos casos expressam mesmo a "consciência e a opinião da empresa jornalística". No entanto, em Portugal os editoriais "tendem a ser assinados pelos directores, desresponsabilizando a empresa e estrutura acionista" (Letria, 1999, p. 69).

Em sentido diverso ao entendimento de Letria, consideramos que o editorial assinado não o torna num mero artigo de opinião do jornalista que é diretor, e por isso não descompromete nem o jornal nem os seus donos. Qualquer publicação implica civil e criminalmente o jornal e seus titulares. O diretor é alguém da confiança dos proprietários e o representante destes na redação (Gradim, 2000, pp. 39-40) e perante os leitores. As cada vez mais complexas rotinas produtivas de um jornal tornam pouco praticável que diariamente se concertem ideias e visões sobre um determinado acontecimento, entre diretor, diretores-adjuntos e subdiretores, para a produção de um editorial de assinatura coletiva.

Os leitores esperam que o seu jornal se pronuncie, num ou mais editoriais, sobre as grandes questões que agitam o mundo, o País ou a sua aldeia, e por isso um editorialista deve assumir desassombradamente essa tarefa - emitir opiniões e orientações rigorosas e fundamentadas, de preferência num texto curto e de leitura agradável (Gradim, 2000, p. 82).

Os órgãos de comunicação social são mediadores entre os vários atores no espaço público. Através dos seus discursos contribuem para a formação da opinião pública, difundindo ideias e fomentando a sua discussão no espaço público. "É nos meios da comunicação social que circula o discurso da opinião pública e é desses meios que ele transita para os restantes campos da vida social como discurso eficaz de legitimação e homegeneização do tecido social" (Rodrigues, 1999, p. 46).

Pela sua natureza e pelos recursos discursivos de que se socorre, o editorial é dos géneros jornalísticos que mais podem contribuir para a introdução no espaço público de temas para discussão e, por essa via, estimular o desenvolvimento de esferas públicas. Nesse sentido, são de "extrema importância o rigor da argumentação, a clareza das deduções, a lucidez da análise e a justeza das conclusões” (Gradim, 2000, p. 85). 
Frames COVID-I9 no Estado de Emergència:

análise dos editoriais de três jornais portugueses

No entanto, tal como em relação às noticias, "o editorialista sabe que o leitor acabará por chegar às suas próprias conclusões, concordando ou não com ele" e que, sem infringir os limites éticos, o diretor pode expressar "[t]odas as [opiniões] que não violem os princípios contidos no seu estatuto editorial e que inspiram diariamente o trabalho da Redacção" (Gradim, 2000, p. 84).

O leitor procura no editorial uma opinião sobre aquilo que é mais relevante dos acontecimentos do quotidiano, esperando que o editorialista consiga identificar o que "é decisivo e gerador de consequências"(Armañanzas \& Noci, 1996, p. 95), desenvolvendo raciocínos e argumentos sobre as causas e efeitos. O editorial desempenha ainda uma ação persuasiva, procurando convencer o leitor das ideias que apresenta.

De acordo com os mesmos autores, poderão apontar-se duas classes de editoriais: os explicativos e os de opinião. "No primeiro caso os editoriais explicam e interpretam; no segundo, argumentam e solicitam um compromisso do leitor" (Armañanzas \& Noci, 1996, p. 96).

No seu Livro de Estilo, o Público (1998, p. 93) divide a opinião expressa no jornal em três géneros: o editorial (assinado por elemento da direção editorial), o comentário (por um diretor, editor ou jornalista) e a opinião (por convidado).

Estes três géneros têm como denominador comum a brevidade dos textos, a interpretação clara e incisiva dos factos e, naturalmente, a opinião do autor sobre a matéria em causa. Essa opinião deverá ser sempre devidamente fundamentada. (...) A independência de espírito, a irreverência e o desassombro polémico são necessários à vitalidade do jornal, mas não é admissível a utilização de uma linguagem panfletária ou insultuosa (Público, 1998, p. 93).

Citando Luiz Beltrão, Anabela Gradim classifica os editoriais em relação à tipologia como 'preventivo', se antecipa uma realidade e aponta consequências; de 'ação', se analisa as causas e o desenvolvimento no momento da ocorrência; de 'consequência', quando aborda as repercussões do acontecimento (2000, p. 86).

Quanto ao conteúdo, refere:

o editorial pode ser informativo, esclarecendo o leitor sobre factos ou situações e explicando aspetos que apenas ficaram implícitos na notícia; normativo, que intenta convencer e exortar o leitor a assumir um determinado rumo de ação; e ilustrativo, o que procura aumentar a instrução dos leitores, chamando a aten- 
ção para questões do quotidiano que costumam passar despercebidas (Gradim, 2000, p. 86).

\section{METODOLOGIA}

O corpus reunido para este trabalho é constituído por 48 editoriais publicados sobre o tema COVID-19 em março de 2020 e janeiro de 2021 em três órgãos de comunicação social generalistas: o jornal diário Público, a revista semanal Visão, ambos de âmbito nacional, e o semanário regional da Beira Baixa Reconquista, com sede em Castelo Branco. Dos órgãos nacionais são analisadas as edições impressas e digitais e do regional, apenas a impressa. O primeiro editorial recolhido foi publicado a 4 de março de 2020 e o último a 31 de janeiro de 2021, ambos no Público.

Dado que a produção nos mais diversos géneros jornalísticos sobre temas relacionadas com a pandemia mundial foi avassaladora, para análise selecionaram-se apenas os editoriais cujo tema central foi a COVID-19. Deste modo, não foram considerados editoriais em que o tema surgia em plano secundário ou de contexto, como aconteceu nomeadamente sobre as eleições presidenciais portuguesas, realizadas a 24 de janeiro de 2021.

Optou-se por fazer incidir a recolha no primeiro mês do primeiro confinamento geral da população em Portugal (março 2020), e no primeiro mês do segundo confinamento geral (janeiro de 2021). Deste modo, pretendeu-se identificar tendências, confrontando os resultados de cada um dos períodos.

Para este trabalho, escolheram-se órgãos de comunicação social com linhas editoriais distintas, públicos / audiências de amplitudes diferentes, e de periodicidades desiguais, procurando assim identificar se às suas variáveis de forma corresponderão também variáveis de conteúdo e de discurso. Embora o Público e Visão sejam órgãos generalistas de âmbito nacional, diferenciam-nos as agendas noticiosas e o facto de o jornal procurar um acompanhamento diário dos acontecimentos, e a revista, um tratamento semanal de assuntos considerados relevantes. O semanário Reconquista, além de ter uma periodicidade semanal, tem uma agenda de assuntos regionais e caracteriza-se por ser um órgão de informação geral de inspiração cristã (propriedade da Fábrica da Igreja da Paróquia de S. Miguel da Sé e atualmente é dirigido pelo padre Agostinho Dias). 
Frames COVID-I9 no Estado de Emergència:

análise dos editoriais de très jornais portugueses

Optou-se pelo método de abordagem quantitativa e da técnica de análise de conteúdo. Procurou-se saber quantos editoriais foram publicados, e, em cada um dos media incluídos no estudo, a frequência com que surgem determinadas características e que diferenças foram encontradas entre os dois períodos de confinamento geral da população, março de 2020 e janeiro de 2021. A partir dos dados apurados, procurou-se avaliar a possibilidade de se estabelecerem inferências.

A análise de conteúdo é uma técnica que se desenvolveu nos Estados Unidos a partir do início do século XX, particularmente por ação da Escola de Jornalismo de Columbia. Os estudos empíricos de análise de conteúdo para a investigação políti$\mathrm{ca}$, nomeadamente da propaganda, tiverem grande incremento no período das duas guerras mundiais (Bardin, 1995, pp. 15-16).

Para classificar os dados de observação, seguiu-se uma metodologia empírica inspirada nas propostas de James W. Tankard, de identificação das frames a partir de palavras-chave, e foi elaborada uma lista de frames (Gradim, 2016, pp. 74-75).

A partir das orientações extraídas da literatura, optou-se por definir quatro unidades de observação: 'Enquadramento', 'Categoria Temática', 'Subtema' e 'Posicionamento'.

Os enquadramentos correspondem às três 'janelas' interpretativas da pandemia. Pelas decisões restritivas de direitos e liberdades fundamentais decretadas pelos poderes do Estado para controlar a propagação do vírus, entendeu-se que "Legitimação Política" deveria figurar a par das expectáveis "Questão Sanitária" e "Impacto Social.

Para a inferência do posicionamento dos editoriais seguiram-se as orientações de Laurence Bardin, começando por identificar "núcleos de sentido" nos discursos dos editorialistas, e de seguida quantificaram-se frequências e ponderou-se a sua direção: favorável, desfavorável ou neutra (1995, pp. 103-116). 


\section{Figura 1}

Esquema de Análise. Fonte: Elaboração própria.
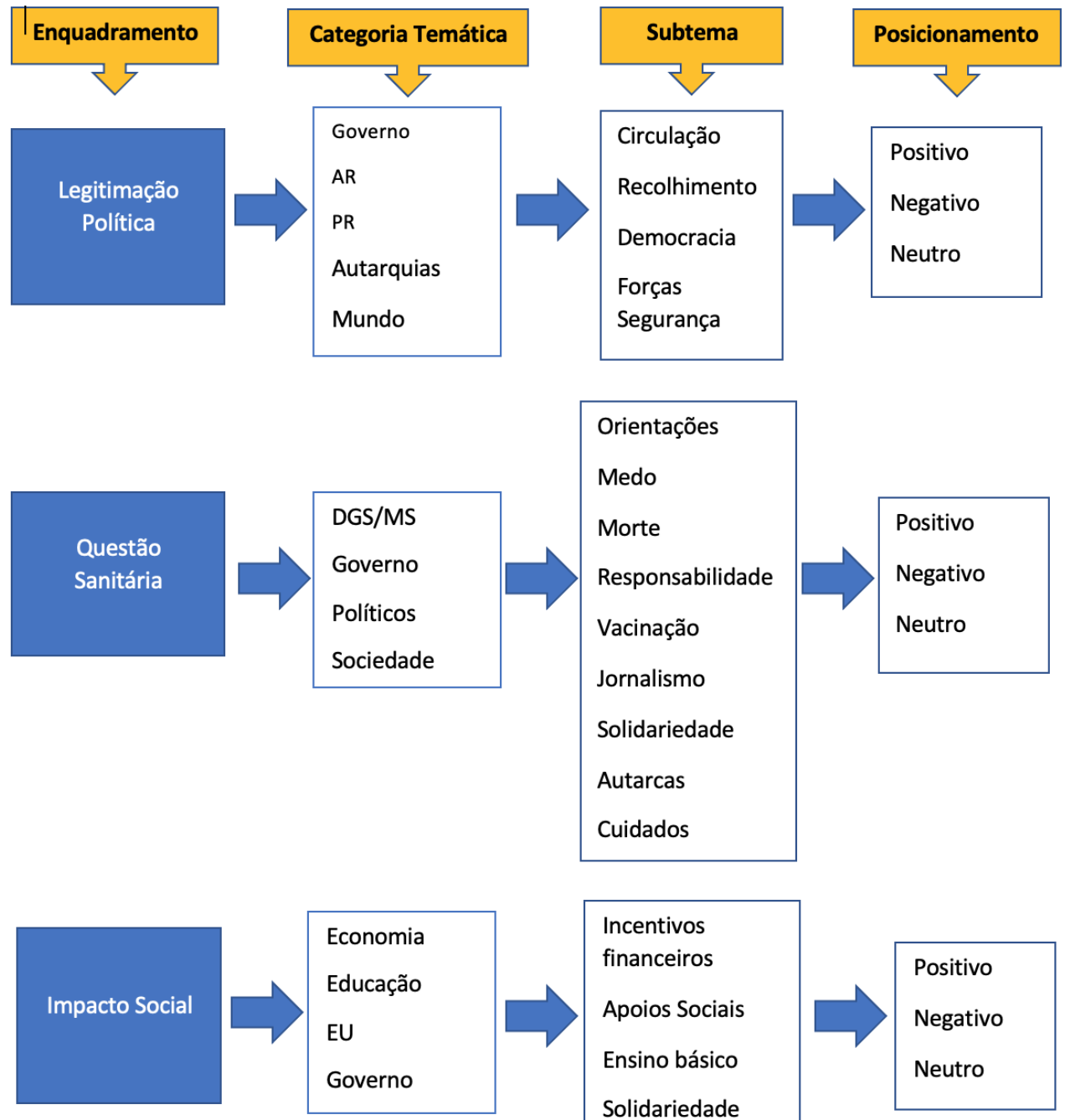

Incentivos
financeiros
Apoios Sociais
Ensino básico
Solidariedade
Responsabilidade

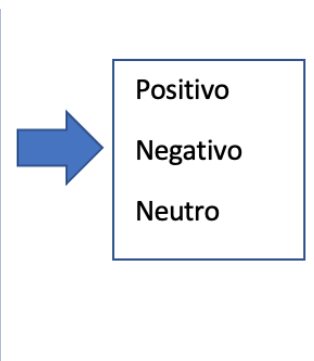

Procurou-se investigar desde quando e quantas vezes ao longo do período de análise foram publicados editoriais sobre COVID-19 em cada um dos três media e quais os temas mais referenciados. Procurou-se indagar ainda que padrões de abor- 
Frames COVID-I9 no Estado de Emergència:

análise dos editoriais de très jornais portugueses

dagem se identificam na pesquisa empírica e se eles variam entre o primeiro confinamento e o segundo confinamento.

De acordo com a pesquisa aqui realizada, e seguindo o guião de análise de conteúdo, identificam-se três grupos de variáveis (Cunha, 2012, p. 84): variáveis de forma (designação do meio, suporte, autoria, data), variáveis de conteúdo (Categoria Temática, Subtema) e variáveis de discurso (enquadramento, posicionamento).

\section{RESULTADOS}

O corpus analisado foi publicado entre 4 e 31 de março de 2020 (30 editoriais) e 5 e 31 de janeiro de 2021 (18 editoriais).

\section{Gráfico 1}

Número de Editoriais por Ano, por Meio e por Suporte

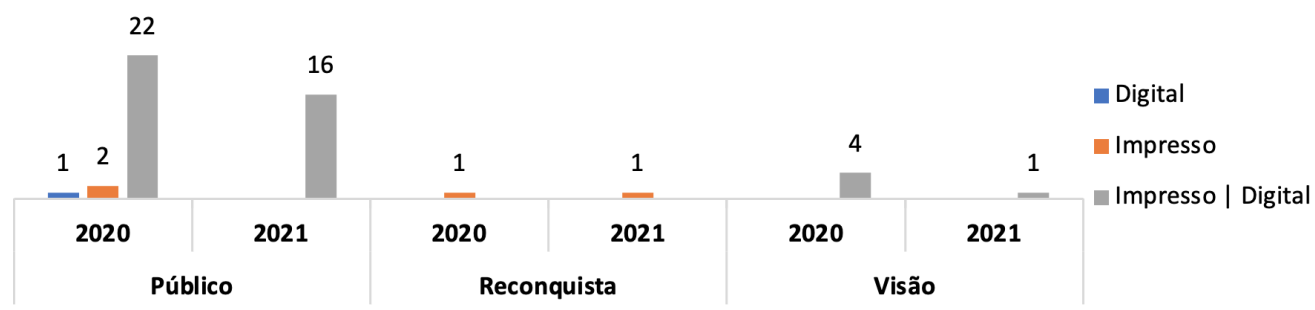

Do total dos 48 editoriais recolhidos, como se evidencia no gráfico n. ${ }^{\circ} 1,41$ foram publicados no diário Público $(85,4 \%)$, cinco na revista semanal Visão $(10,4 \%)$ e dois no semanário regional Reconquista (4,2\%). Em março de 2020, no Público foram publicados 25, na Visão quatro e no Reconquista um. Em janeiro de 2021, o Público publicou 16, a Visão e Reconquista um cada.

À exceção do Reconquista, cuja recolha incidiu apenas no jornal impresso, nos outros órgãos foram analisados os editoriais publicados também na edição digital. $\mathrm{Na}$ Visão, os cinco selecionados foram publicados nas duas plataformas. No Público, constatou-se que dois editoriais foram apenas publicados na edição impressa e um exclusivamente na digital. Os restantes apareceram em ambas as plataformas. 


\section{Gráfico 2}

Variável Autoria dos Editoriais por Meio e Ano

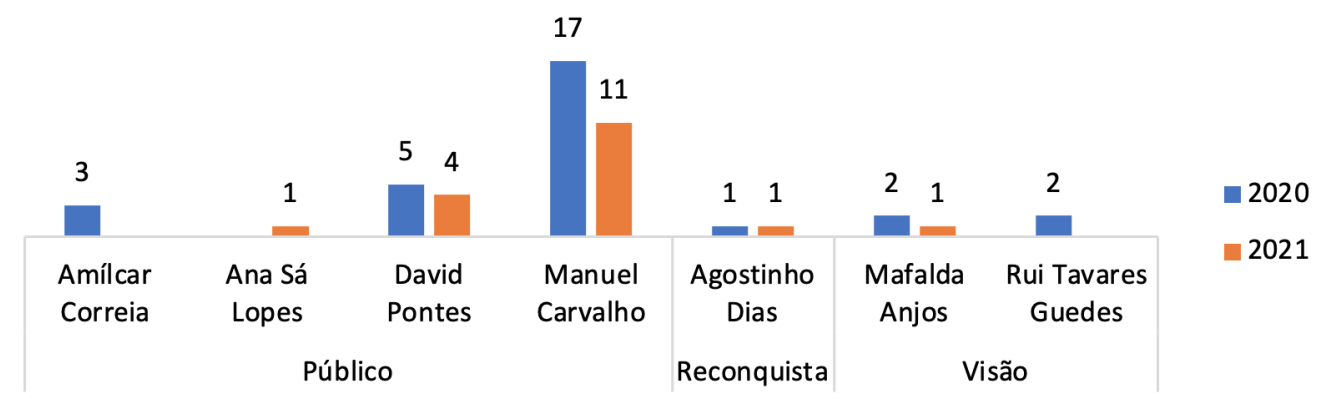

No que respeita à variável autoria por meio e ano, o gráfico $n .^{\circ} 2$ revela que o diretor do Público, Manuel Carvalho, assinou 58,3\% (28) do total dos editoriais analisados, e 68,3\% (28) dos publicados no seu jornal. Na mesma publicação, os diretores adjuntos David Pontes, Amílcar Correia e Ana Sá Lopes publicaram, respetivamente, nove $(18,8 \%)$, três $(6,3 \%)$ e um (2,1\%). Na Visão, a diretora Mafalda Anjos assinou três $(6,3 \%)$ e o diretor executivo Rui Tavares Guedes dois (4,2\%). No Reconquista, o padre Agostinho Dias publicou também dois $(4,2 \%)$.

Constata-se que os diretores Manuel Carvalho, no Público, e Agostinho Dias, no Reconquista, se assumiram os grandes porta-vozes da linha ideológica das suas publicações, enquanto na Visão esse protagonismo foi repartido semanalmente entre os dois responsáveis editoriais.

\section{Gráfico 3}

Variável Categoria Temática por Meio e Ano

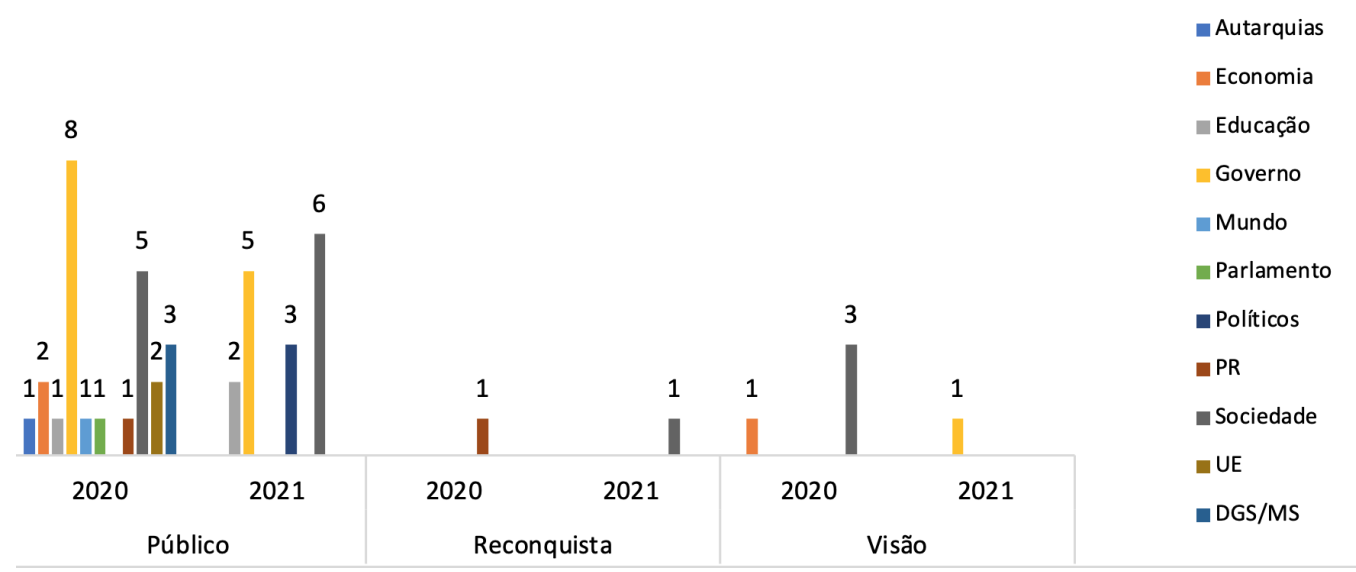


Frames COVID-I9 no Estado de Emergência:

análise dos editoriais de très jornais portugueses

No grupo da "Variável Conteúdo" sobressaem na variável "Categoria Temática" (Gráfico n. ${ }^{\circ}$ 3) os itens "Sociedade" e "Governo", o primeiro totalizando 15 ocorrências $(31,3 \%)$ e o segundo $14(29,2 \%)$. No seu conjunto ultrapassam os $60 \%$. Se contabilizarmos por período, teremos em março de 2020 oito ocorrências (26,7\%) em cada um dos temas "Governo" e "Sociedade". Em janeiro de 2021 são sete ocorrências "Sociedade" (38,9\%) e seis "Governo" (33,3\%). Em março de 2020, aparecem por três vezes (10\%) os temas "DGS/MS" (Direção-Geral da Saúde/Ministério da Saúde) e "Economia". Em janeiro de 2021, com três ocorrências apenas, surge o tema "Políticos" (16,7\%) e com duas (6,7\%), "EU” (União Europeia) e "PR" (Presidente da República), em março de 2020. Igualmente duas ocorrências "Educação" (11,1\%) registam-se em janeiro de 2021.

Perante a situação pandémica, os editorialistas procuraram analisar e explicar a situação complexa, identificando como principais atores os cidadãos e o Governo. Aos primeiros alerta-os para a importância vital de adotarem certos comportamentos para conter a propagação e a assumirem a obrigação de confinamento, e ao Governo, a vigiar-lhe a gestão da crise sanitária e económico-social. Os editoriais cumprem as funções de explicar os factos e de formular juízoes, identificadas por Armañanzas \& Noci, e enquadram as tipologias de "ação" e "consequência" apontadas por Luiz Beltrão. 


\section{Gráfico 4}

Variável Subtema por Meio e Ano

\begin{tabular}{|c|c|c|c|c|c|c|}
\hline & 2020 & 2021 & 2020 & 2021 & 2020 & 2021 \\
\hline & \multicolumn{2}{|c|}{ Público } & \multicolumn{2}{|c|}{ Reconquista } & \multicolumn{2}{|c|}{ Visão } \\
\hline Apoios Sociais & 1 & & & & & \\
\hline Autarcas & 1 & & & & & \\
\hline Circulação & 3 & & & & & \\
\hline Cuidados & 1 & & & & & \\
\hline Democracia & 1 & & & & & \\
\hline Ensino Básico & & 2 & & & & \\
\hline — Forças de Segurança & 1 & & & & & \\
\hline Incentivos Financeiros & 2 & & & & & \\
\hline Jornalismo & 1 & & & & 1 & \\
\hline Medo & 1 & & & & & \\
\hline Morte & & 1 & & & & \\
\hline Orientações & 2 & 2 & & & & \\
\hline Recolhimento & 6 & 1 & 1 & & & \\
\hline Responsabilidade & 1 & 6 & & 1 & 2 & 1 \\
\hline Solidariedade & 4 & & & & 1 & \\
\hline Vacinação & & 4 & & & & \\
\hline
\end{tabular}

No grupo da "Variável Conteúdo" sobressaem na variável "Subtema" (Gráfico n. ${ }^{\circ}$ ) os itens "Recolhimento", com sete (23,3\%) ocorrências em março de 2020 e uma (5,6\%) em janeiro de 2021, e "Responsabilidade", com três (10\%) ocorrências no mesmo período de 2020 e oito $(44,4 \%)$ ocorrências em igual período de 2021. Em 2020, aparecem "Solidariedade" cinco vezes (16,7\%) e "Circulação" por três vezes (10\%). Em 2021, o subtema "Vacinação" ocorre quatro vezes $(22,2 \%)$.

Os tópicos identificados no subtema, que são uma espécie de palavras-chave da vivência dos períodos mais agudos da pandemia, indiciam que os editorialistas assumem aquilo que Armañanzas \& Noci designam de "guardiães não oficiais da consciência pública”. 
Frames COVID-I9 no Estado de Emergència:

análise dos editoriais de très jornais portugueses

\section{Gráfico 5}

Correspondência entre Categoria Temática e Subtema

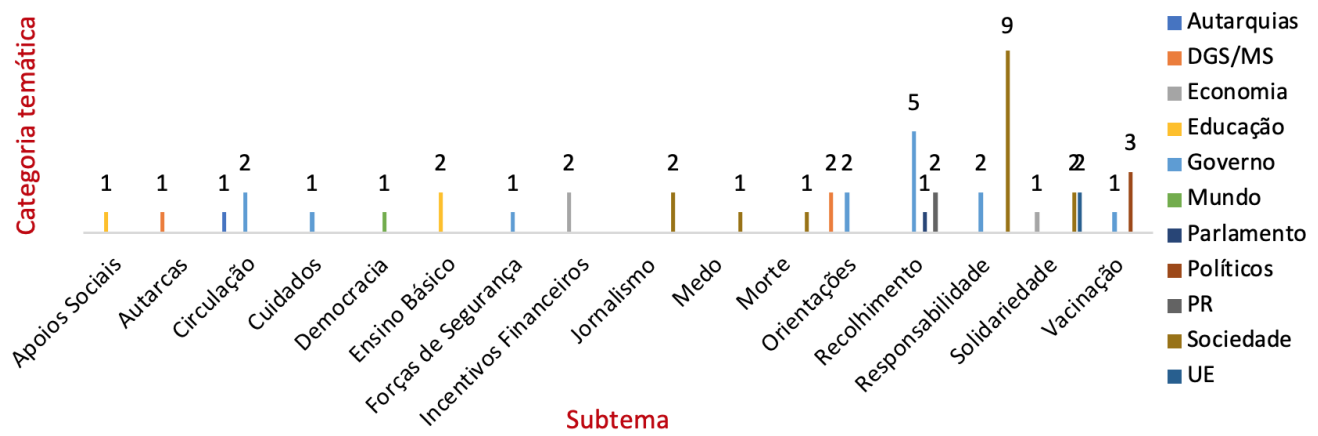

As relações entre as categorias temáticas e os subtemas são apresentadas no gráfico n. ${ }^{\circ}$ 5: "Autarquias" (circulação), "DG/MS" (autarcas, orientações), "Economia" (incentivos financeiros, solidariedade), "Educação" (apoios sociais, ensino básico), "Governo" (circulação, cuidados, forças de segurança, orientações, recolhimento, responsabilidade, vacinação), "Mundo" (democracia), "Parlamento" (recolhimento), "Políticos" (vacinação), "PR" (recolhimento), "Sociedade" (jornalismo, medo, morte, responsabilidade, solidariedade), "UE” (solidariedade).

\section{Gráfico 6}

Enquadramentos por Ano e por Meio

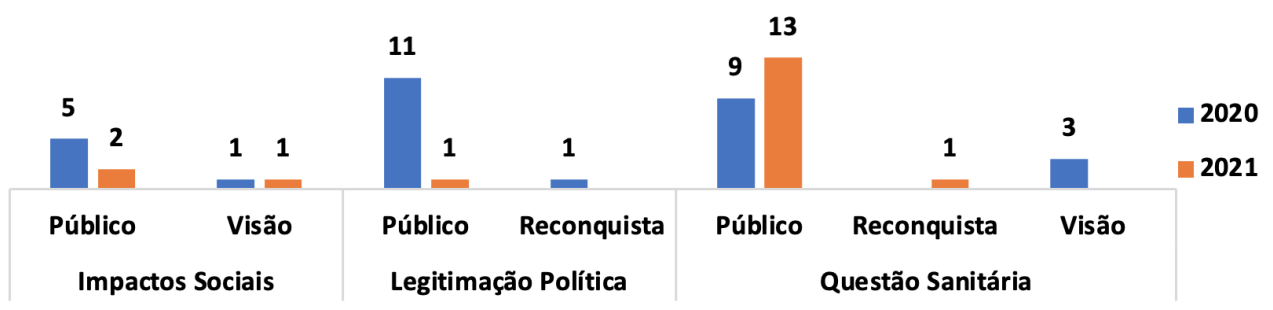

No grupo "Variável Discurso", como se constata no gráfico n. o 6, "Legitimação Política" é o enquadramento escolhido em março de $2020 \mathrm{em} 44 \%$ (11) dos editoriais do Público e em 50\% (1) do Reconquista. A Visão omite este enquadramento. Em março de 2020, a "Legitimação Política" representa 40\% do total dos editoriais, percentagem igual à de "Questão Sanitária", para isso contribuindo a opção de enquadramento de três das quatro publicações de editorialistas da Visão. No mesmo período, o "Impacto Social" é enquadrado em seis editoriais (20\%), cinco no Público e um na Visão. 
No período de janeiro de 2021, o enquadramento "Questão Sanitária" é dominante (77,8\%), com 14 (13 no Público e um no Reconquista) de um total 18 publicações. "Impacto Social" representa 16,7\% (dois editoriais no Público e um na Visão). A "Legitimação Política" é opção de enquadramento em um (5,6\%) editorial do Público.

Duas hipóteses interpretativas poderemos aqui apresentar para esta mudança nas opções de enquadramento, do primeiro para o segundo confinamento, ou procurar uma explicação na conjugação de ambas. Uma das hipóteses poderá relacionar-se com o momento da pandemia, e uma outra, com as opções jornalísticas de representação da realidade.

O problema sanitário em janeiro de 2021 era extremamente grave em Portugal, um dos países da Europa com mais casos de infetados por 100 mil habitantes, e com serviços de saúde à beira da rutura ${ }^{1}$. Era um período em que os editorialistas questionavam a gestão político-administrativa da pandemia. A suspensão de algumas regras do Estado de Emergência no período do Natal tinha sido um fracasso ${ }^{2}$. O problema de saúde pública estava no seu auge, o que torna compreensível o foco dos editorialistas na "Questão Sanitária".

A segunda hipótese radica num conjunto de questões intrínsecas ao campo jornalístico. Os framings ou enquadramentos têm um ciclo de vida, e quando os acontecimentos se estendem no tempo necessitam de reactualizações para assegurarem o efeito de novidade, que está inerente à produção jornalística e à atenção dos leitores.

[T]êm de ser objeto de sucessivos "reframings" ou "frame change". Ou seja, pela sua natureza, não podem constantemente debitar o mesmo, pelo que um assunto para se manter vivo precisa de frescura de novas perspetivas acerca do seu significado e alcance, daí o padrão de loop que por vezes se verifica no enquadramento de eventos que obtêm um certo grau de permanência no palco mediático (Gradim, 2016, p. 88).

Poderá interpretar-se ainda como opção de reframing uma parte dos editoriais de janeiro de 2021, em que o tema passa a ser as eleições presidenciais e a pandemia o contexto.

1 Disponível em: https://www.publico.pt/2021/01/31/sociedade/noticia/covid19-portugal-regista-9498novos-casos-303-mortes-1948690

2 Disponível em: https://www.publico.pt/2021/01/15/sociedade/noticia/confinamento-faz-conta-1946557 
Frames COVID-I9 no Estado de Emergència:

análise dos editoriais de très jornais portugueses

\section{Gráfico 7}

Posicionamento por Meio, Autor e aAno

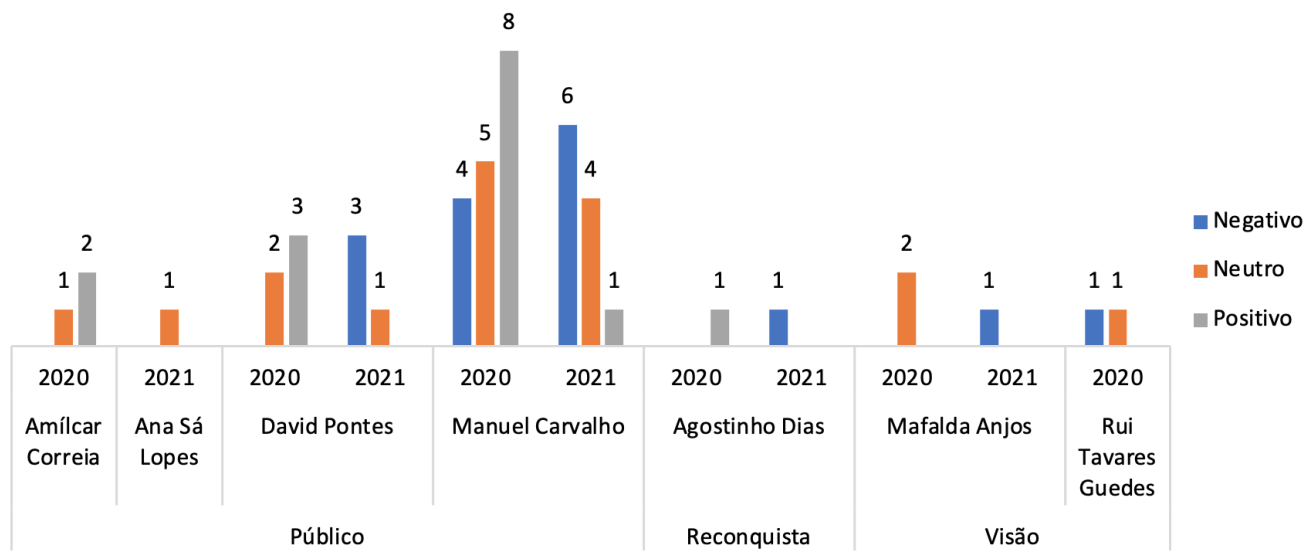

O posicionamento global positivo é de 31,3\% (15 editoriais), o negativo de 33,3\% (16) e o neutro de $35,4 \%$ (17). Em março de 2020, o posicionamento positivo foi de $46,7 \%$ (14 editoriais), o negativo de $16,6 \%$ (5) e o neutro, de $36,7 \%$ (11). Nos editoriais de janeiro de 2021, o posicionamento positivo foi de 5,6\% (1), o negativo de $61,1 \%$ (11) e o neutro, de $33,3 \%$ (6).

O diretor do Público, Manuel Carvalho, autor de 28 editoriais (58,3\%) incluídos nesta pesquisa, é quem mais oscila no posicionamento positivo, passando de 8 ocorrências, em março de 2020, para uma ocorrência, em janeiro de 2021. O posicionamento negativo, entre os mesmos períodos, passa de quatro para seis, e o neutro, de cinco para quatro. Grandes mudanças de posicionamento também evidencia o diretor-adjunto do Público David Pontes, que em 2020 publicara três editoriais com posicionamento positivo e dois neutros, mas apresenta em 2021 três de teor negativo e um neutro. Estes dados assumem maior significado comparativo se atendermos ao número de editoriais em março de 2020 (30) e janeiro de 2021 (18). 


\section{Gráfico 8}

Enquadramentos e Posicionamento, por Ano

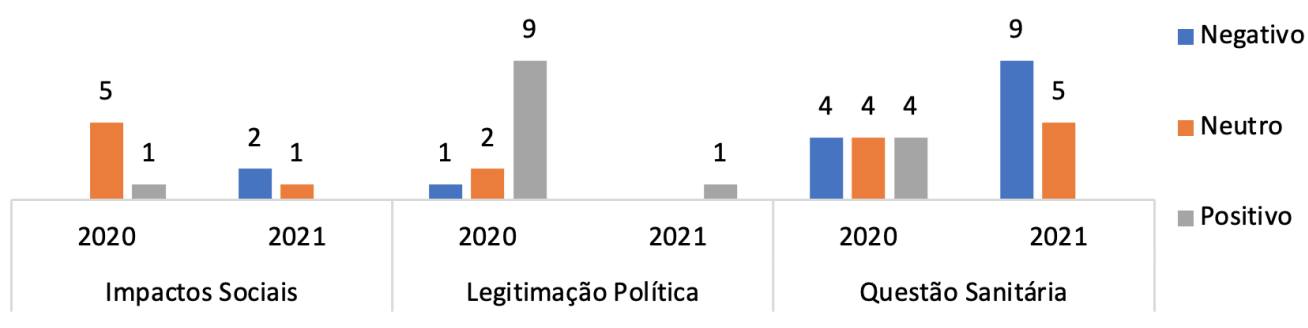

Da análise do gráfico n. ${ }^{\circ} 8$, a apreciação geral é a de que o enquadramento "Legitimação Política" merece um posicionamento positivo dos articulistas, "Questão Sanitária" suscita um posicionamento negativo e "Impacto Social", um posicionamento neutro.

Os resultados evidenciados vão ao encontro das asserções da sociologia que apontam para o poder do jornalismo de colocar no espaço público temas que considera importantes para os cidadãos e a vivência democrática. O enquadramento "Legitimação Política" indicia uma aproximação da agenda mediática à agenda política, nomeadamente no referente à contração de direitos e liberdades fundamentais, para conter a epidemia. O enquadramento "Questão Sanitária" remete para um atributo fundamental do jornalismo, o de vigilância do poder político e, no caso concreto na gestão pandemia, denunciando erros, falhas, indecisões, ausência de medidas e atos de corrupção no processo de vacinação.

\section{Gráfico 9}

Enquadramentos e Categoria Temática, por Ano

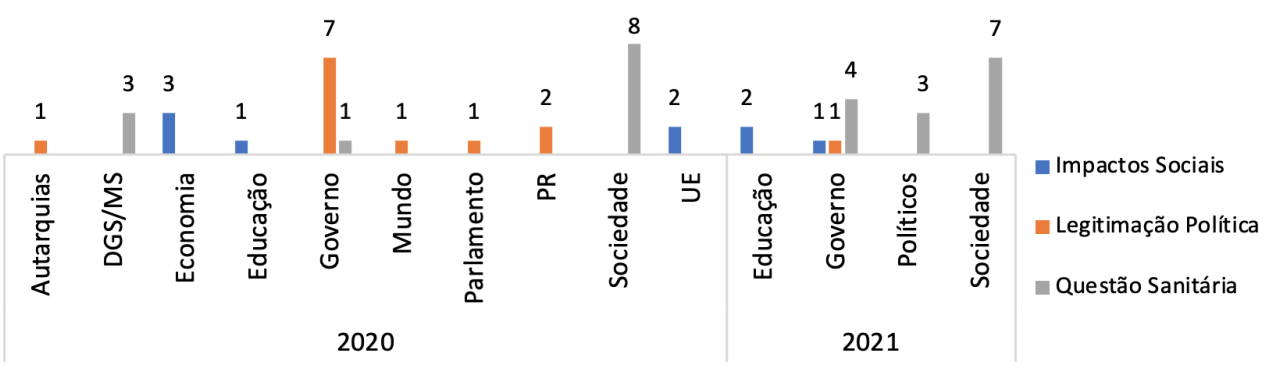


Frames COVID-I9 no Estado de Emergència:

análise dos editoriais de três jornais portugueses

Como se observa no gráfico n. ${ }^{\circ}$ 9, o enquadramento "Questão Sanitária" totaliza $26(54,2 \%)$ ocorrências na soma dos dois períodos. Tem como categoria temática dominante 'Sociedade', com 15 ocorrências (31,3\%). Além desta abarca ainda 'Governo', com cinco (10,4\%), 'DGS/MS', três (6,3\%) e 'Políticos', três (6,3\%). O enquadramento "Legitimação Política” totaliza 15 (31,3\%) ocorrências, divididas por 'Governo', 8 (16,7\%), 'PR', duas (4,2\%), 'Parlamento', uma (2,1\%), 'Autarquias', uma (2,1\%), 'Mundo', uma (2,1\%). O enquadramento "Impacto Social" abrange nove ocorrências $(18,8 \%)$, distribuídas por 'Educação', três (6,3\%), 'Economia', três (6,3\%), 'UE', duas $(4,2 \%)$ e 'Governo', uma (2,1\%).

\section{CONSIDERAÇÕES FINAIS}

Da análise dos resultados, um dado sobressai de imediato, é o de que no primeiro confinamento, em março de 2020, a COVID-19 foi o incontornável acontecimento mediático (Gráfico n. ${ }^{\circ}$ ), sendo tema para os editoriais das quatro edições semanais da Visão e atingiu os 25 no Público, jornal que apresentou no dia 21 dois distintos, na edição impressa e online, assinados por Manuel Carvalho e Amílcar Correia. A importância atribuída ao assunto foi tal que habitualmente os textos assinados pelos diretores na edição digital surgiam com o título de rubrica "Editorial Coronavírus".

Relativamente ao segundo confinamento, o número de editoriais sobre a COVID19 decresce para quase metade (18) porque o mês de janeiro de 2021 foi fértil em outros acontecimentos de impacto nacional, as eleições presidenciais, e internacional, a tomada de posse do presidente dos EUA Joe Biden. Em praticamente todos os editoriais sobre as eleições presidenciais portuguesas, que tinham a novidade de um candidato de extrema-direita, aparecia o tema da pandemia ao abordar os discursos dos candidatos, o modelo de campanha e os constrangimentos no ato de votar.

Os enquadramentos escolhidos para os editoriais em março de 2020 são dominantemente, em igual percentagem (40\%), pela "Legitimação Política" e "Questão Sanitária” (Gráfico n. ${ }^{\circ}$ 6). Os editorialistas debruçavam-se a analisar dois quadros conexos, as restrições a direitos e a liberdades fundamentais com o isolamento social obrigatório para se quebrarem cadeias de contágio, e as medidas profiláticas e de tratamento da doença.

No segundo confinamento, o enquadramento dominante é "Questão Sanitária" (77,8\%) e "Legitimação Política" é já residual (5,5\%). Em janeiro de 2021, Portugal 
apresentava dos piores resultados a nível internacional de contágio e de mortes por 100 mil habitantes.

Comparativamente, o enquadramento "Impacto Social" teve baixa expressão nos dois períodos, 20\% em março de 2020 e 16,7\% em janeiro de 2021. A salvaguarda da vida aparecia como o valor supremo, e ao nível das empresas, do emprego e do ensino, o Governo procurava apresentar medidas financeiras de mitigação dos efeitos da pandemia.

Quanto ao posicionamento dos editoriais (Gráfico n. ${ }^{\circ}$ 7), em março de 2020 é predominantemente positivo (46,7\%) e em janeiro de 2021, é dominantemente negativo $(61,1 \%)$. No primeiro confinamento, embora apontando falhas na abordagem das instituições e da sociedade à pandemia, os editorialistas procuram interpretar e explicar a comunicação política, contribuindo para o esforço coletivo de abordar um 'inimigo' ainda pouco conhecido. No segundo confinamento, não perdoam ao Governo a incapacidade de mobilizar os cidadãos, de gerir o programa de vacinação, do "relaxamento" no período do Natal, de deixar a pandemia resvalar para uma situação incontrolável. Culpam ainda os políticos por ações demagógicas e populistas relacionadas com o programa de vacinação ${ }^{3}$.

De um modo geral, a opinião expressa nos editoriais analisados neste artigo parte da interpretação e crítica do discurso político e da ação política. Manuel Carvalho, diretor do Público, a 14 de março de 2020 assina um editorial que, de certo modo, é matricial desta linha de abordagem. Sob o título "O coronavírus e o regresso do Estado", escreve: "Nos dias de chumbo que vivemos, só os poderes do Estado conseguem impor um estado de excepção. Temos de o aceitar por absoluta inexistência de alternativas"4.

No entanto, também é Manuel Carvalho que assina alguns dos que se distanciam daquela premissa, fazendo jus à condição de autor de 58,3\% desses artigos jornalísticos que constituem o corpus do artigo. Num deles, a 21 de março de 2020, reflete sobre o jornalismo e as dificuldades em prosseguir a missão de serviço público no contexto agravado pela pandemia sem o apoio dos assinantes, os cidadãos leitores ${ }^{5}$.

O exercício do jornalismo é também tema de um editorial publicado na Visão por Rui Tavares Guedes, em que se insurge contra a prática de órgãos de comunica-

3 Disponível em: https://www.sns.gov.pt/wp-content/uploads/2021/01/Apresentacao_PlanoVacinacao_2020. 01.28_VFINAL.pdf

4 Disponível em: https://www.publico.pt/2020/03/14/sociedade/editorial/coronavirus-regresso-estado-1907687 5 Disponível em: https://www.publico.pt/2020/03/21/opiniao/editorial/carta-leitores-leitoras-publico-1908717 
Frames COVID-I9 no Estado de Emergència:

análise dos editoriais de três jornais portugueses

ção social que ao abordar a COVID-19 "repetem o discurso habitual dos populistas, sempre repleto de estereótipos xenófobos e das teorias da conspiração mais delirantes, de forma a tentar alastrar o medo e o preconceito em relação aos "outros", recorrendo a metáforas como a do "vírus da China".

O medo e a morte, que qualquer discurso associa a um acontecimento pandémico, estão quase ausentes nos editoriais estudados. É Manuel Carvalho que assina dois em que no subtema se codificam ambos os conceitos.

O medo é utilizado na retórica argumentativa de "A hora negra da COVID-19", publicado a 4 de março de 2020, precisamente o primeiro editorial do corpus de análise deste artigo, em que afirma: "Temos à nossa frente um terrível desafio para vencer. Só o venceremos aceitando que haverá perdas humanas e conservando até ao limite as nossas habituais formas de viver em sociedade"7.

A morte está presente no editorial "Os rostos da nossa tristeza comum", publicado a 23 de janeiro de 2021, a acompanhar um dossier temático em torno de figuras públicas nacionais e de âmbito local que sucumbiram à COVID-199. A morte é ausência, é aquele que deixou de ser visto. Olhar para os seus rostos "ajuda a sair da frieza da aritmética", afirma Manuel Carvalho, porque as fotos, como diria Susan Sontag, "são meios de tornar 'real' (ou 'mais real') assuntos que as pessoas socialmente privilegiadas, ou simplesmente em segurança, talvez preferissem ignorar" (2003, p. 12).

As atitudes sociais perante a doença e o risco da morte são evidenciadas num texto publicado a 14 de janeiro no Reconquista pelo seu diretor, o padre Agostinho Dias. O articulista insurge-se contra denúncias às autoridades de casos de infetados que não cumpriam o isolamento obrigatório, e argumenta com uma reinterpretação de escritos bíblicos, dizendo ser uma maneira de os "excluir da sociedade", tal como aconteceu com os leprosos em Israel, no tempo de Cristo ${ }^{10}$.

Aos discursos de uma pandemia associa-se um conjunto de conceitos relacionados com a sua principal caraterística, a propagação. O seu uso recorrente nos discursos jornalísticos desencadeou um efeito de contaminação em narrativas sobre outros

6 Disponível em: https://visao.sapo.pt/opiniao/2020-03-05-51-anos-de-indecisao-e-um-virus-global/ 7 Disponível em: https://www.publico.pt/2020/03/04/sociedade/editorial/hora-negra-covid19-1906353?fbcl id=IwAR1PFMcKmYl5HUrjsJprz07byVmi5kRokcjK2GUyKqOtQ6aCCI8ZcFwXzG8

8 Disponível em: https://www.publico.pt/2021/01/23/sociedade/noticia/rostos-tristeza-comum-1947571

9 Disponível em: https://www.publico.pt/2021/01/23/sociedade/noticia/luisa-vitor-pedro-helena-luisvalerio-vidas-perdemos-coronavirus-1947384

10 Disponível em: https:/www.reconquista.pt/articles/retratos-os-leprosos-de-hoje 
temas. Embora não fazendo parte do âmbito do presente estudo, foram encontrados alguns casos quando se procedia à seleção para a criação do seu corpus, nomeadamente em dois editoriais do Público publicados em janeiro de 2021 pelo seu diretor-adjunto Amílcar Correia. O articulista recorre a importações do léxico comum da pandemia quando titula que "A xenofobia é um vírus"11, e ao opinar sobre a invasão da sede do Congresso dos EUA por ativistas afetos ao ex-presidente Donald Trump, com os seguintes argumentos: "Num distanciamento profiláctico e ético, muitas empresas estão a despedir alguns desses vândalos"12.

Retomando a classificação dos editoriais avançada por Anabela Gradim (2000, p. 86), quanto à tipologia encontramos no corpus, dos três tipos que enuncia, 'preventivo', de 'ação' e de 'consequência'. Uns antecipam a realidade e apontam consequências, outros analisam as causas e o desenvolvimento no momento, e outros ainda refletem sobre as repercussões dos acontecimentos. Quanto ao conteúdo (Gradim, 2000 , p. 86), no corpus encontram-se predominantemente os 'informativos', a explicar factos das notícias, e 'normativos', a incitar os leitores a determinada ação. No entanto, como 'ilustrativo', com vocação formativa, poderá apontar-se o editorial de Rui Tavares Guedes a denunciar a utilização de estereótipos xenófobos em discursos jornalísticos ${ }^{13}$.

Confrontando os resultados apurados, pese embora a discrepância no número de publicações, não se verificaram diferenças assinaláveis nos temas, nas tipologias e nos conteúdos dos editoriais do Público e da Visão. No Reconquista sobressaiu a matriz cristã do proprietário e do diretor do jornal.

$\mathrm{Da}$ análise dos editoriais, conclui-se ainda que os seus autores se associaram ao objetivo político prioritário de salvar vidas, assumido pelo Governo e executado através da Direção-Geral da Saúde ${ }^{14}$.

Em investigação futura, e sendo o editorial a voz do jornal, seria importante confrontar os resultados apurados em relação ao Público com os de outros jornais diários pertencentes a grupos empresariais com intervenção distinta no espaço mediático.

11 Disponível em: https://www.publico.pt/2021/01/23/sociedade/noticia/xenofobia-virus-1947646 12 Disponível em: https://www.publico.pt/2021/01/10/mundo/noticia/impeachment-trump-questaoetica-1945687

13 Disponível em: https:/visao.sapo.pt/opiniao/2020-03-05-51-anos-de-indecisao-e-um-virus-global/ 14 Disponível em: https://covid19.min-saude.pt/prioridade-do-pais-no-combate-a-pandemia-foi-protegervidas/ 
Frames COVID-I9 no Estado de Emergência:

análise dos editoriais de très jornais portugueses

\section{REFERÊNCIAS}

Armañanzas, E., \& Noci, J. D. (1996). Periodismo y Argumentación. Géneros de opinión. Bilbao: Servicio Editorial Universidad del País Vasco.

Bardin, L. (1995). Análise de Conteúdo. Lisboa: Edições 70.

Borges, S. M. (2021). O que é a Opinião Pública? Em S. M. Borges, R. Baldissera, E. U. Cervi, \& G. H. Moura, O que é Opinião Pública? (pp. 9-37). Forte da Casa: Escolar Editora.

Bourdieu, P. (1997). Sobre a Televisão. Rio de Janeiro: Jorge Zahar.

Camponez, C., Miranda, J., Fidalgo, J., Garcia, J. L., Matos, J. N., Oliveira, M., . . Silva, P. A. (2020). Estudo sobre os Efeitos do Estado de Emergência no Jornalismo no Contexto da Pandemia COVID-19. Relatório. Lisboa: Sopcom.

Cunha, I. F. (2012). Análise dos Media. Coimbra: Imprensa da Universidade de Coimbra. http://dx.doi.org/10.14195/978-989-26-0309-4

Entman, R. M. (1993). Framing: Toward clarification of a fractured paradigm. Journal of Communication, 4(43), 51-58. https://doi.org/10.1111/J.1460-2466.1993. TB01304.X

Esteves, J. P. (2011). Sociologia da Comunicação. Lisboa: Fundação Calouste Gulbenkian.

Ferreira, G. B. (2020). Quando as notícias importam. Fontes, confiança e desinformação em tempos de COVID-19. Em F. R. Cádima, \& I. (. Ferreira, Perspectivas multidisciplinares da Comunicação em contexto de Pandemia (Vol I) (pp. 30-49). Lisboa: Instituto de Comunicaçao da nova: Universidade Nova de Lisboa. https://doi.org/10.34619/66st-jr20

Garcia, J. L. (2020). Introdução. Em J. L. Garcia, T. D. Martinho, Cunha, D. S. da, J. Ramalho, M. P. Alves, ... S. M. Graça, O Choque Tecno-Liberal, os Media e o Jornalismo: Estudos Críticos Sobre a Realidade Portuguesa (pp. 9-24). Coimbra: Almedina. 
Goffman, E. (2006). Frame Analysis: Los marcos de la experiencia. Madrid: Centro de Investigaciones Sociológicas.

Gonçalves, T. (2011). A Abordagem do Enquadramento nos Estudos de Jornalismo. Caleidoscópio: Revista de Comunicação e Cultura(5/6), 157-167.

Gradim, A. (2000). Manual de Jornalismo. Covilhã: Universidade da Beira Interior.

Gradim, A. (2016). Framing, o enquadramento das notícias. Lisboa: Livros Horizonte. Habermas, J. (1997). Direito e Democracia - Entre Facticidade e Validade (Vol. II). Rio de Janeiro: Tempo Brasileiro.

Habermas, J. (2000). O discurso filosófico da modernidade. São Paulo: Martins Fontes.

Kovach, B., \& Rosenstiel, T. (2004). Os Elementos do Jornalismo, O que os profissionais do jornalismo devem saber o e o público deve exigir. Porto: Porto Editora.

Letria, J. (1999). Pequeno Breviário Jornalístico. Lisboa: Editorial Notícias.

Pinto, J. N. (2020). Contágios - 2500 Anos de Pestes. Lisboa: D. Quixote.

Ponte, C. (2004). Leituras das Notícias: Contributos para uma análise do discruso jornalístico. Lisboa: Livros Horizonte.

Público. (1998). Livro de Estilo Público. Lisboa: PÚBLICO, Comunicação Social, SA.

Qin, J. (2015). Hero on Twitter, Traitor on News: How Social Media and Legacy News Frame Snowden. The International Journal of Press/Politics, 20(2), 166-184. https://doi.org/10.1177/1940161214566709

Rodrigues, A. D. (1999). O Campo dos Media. Lisboa: Vega.

Sontag, S. (2003). Diante da dor dos outros. São Paulo: Companhia das Letras.

Traquina, N. (2004). A Tribo Jornalística: uma comunidade transnacional. Lisboa: Editorial Notícias.

Traquina, N. (2007). O que é Jornalismo. Forte da Casa: Quimera.

Tuchman, G. (1985). La producción de la noticia: Estudio sobre la construcción de la realidad. México: GG MassMedia. 
Frames Covid-I9 no Estado de Emergència:

análise dos editoriais de très jornais portugueses

Tuchman, G. (1999). Contando «Estórias». Em N. Traquina, Jornalismo: Questões, Teorias, "Estórias" (pp. 258-262). Lisboa: Vega.

Tuchman, G. (2002). As notícias como uma realidade construída. Em J. P. Esteves, Comunicação e Sociedade - Os efeitos sociais dos meios de comunicação de mas$s a$ (pp. 91-104). Lisboa: Livros Horizonte. 